\title{
Changes in diversity and body size of Onychiurinae (Collembola: Onychiuridae) along an altitudinal gradient in Changbai Mountain, China
}

\author{
Xin Sun ${ }^{1,2}$, Louis Deharveng ${ }^{3,{ }^{*}}$, Anne Bedos ${ }^{3}$, Liang Chang ${ }^{2}$, Stefan Scheu ${ }^{1,4}$, Donghui $\mathrm{Wu}^{2,{ }^{*}}$ \\ 1 J.F. Blumenbach Institute of Zoology and Anthropology, University of Göttingen, 37073 Göttingen, Germany \\ 2 Key Laboratory of Wetland Ecology and Environment, Northeast Institute of Geography and Agroecology, Chinese Academy of Sciences, \\ Changchun 130012, China \\ 3 Institut de Systématique, Évolution, Biodiversité (ISYEB), UMR7205, CNRS, Muséum national d'Histoire naturelle, Sorbonne Université, \\ EPHE, 45 rue Buffon, 75005 Paris, France \\ 4 Center for Sustainable Land Use, University of Göttingen, 37073 Göttingen, Germany
}

\section{ARTICLE INFO}

\section{Article history:}

Received March 4, 2020

Revised April 22, 2020

Accepted May 11, 2020

\section{Keywords:}

Collembola

Elevation

Species richness

Body size

\begin{abstract}
A B S T R A C T
Collembola are among the most abundant and diverse soil animals contributing significantly to major ecosystem processes. Global climate changes in temperature and precipitation are likely to affect their community structure and functioning and this is likely to differ along altitudinal gradients. In this study, changes in richness, abundance, and body size of onychiurin Collembola with altitude have been investigated in the Changbai Mountain range of northeast China. Sampling was carried out on a $30 \mathrm{~km}$ long transect along forested slopes of the Changbai Mountains. Standardized samples were taken from 800 to $1700 \mathrm{~m}$ at seven altitudinal levels. More than 5000 specimens of Onychiurinae representing 13 species were collected, making Onychiuridae (with the sole subfamily Onychiurinae in Changbai) the most abundant Collembolan family in the area. The number of species of Onychiurinae slightly increased along the altitudinal gradient. The average number of species per sample, but not the total abundance, changed significantly but not monotonically with altitude. Body size of Onychiurinae species decreased significantly with increasing altitude contradicting Bergmann's rule. Furthermore, the abundance of the three body-size groups differentially responded to increasing altitude, with the abundance of the large body-size group decreasing and the abundance of the small body-size group increasing. Our results suggest that the distribution patterns of Collembola along the altitudinal gradient are complicated and may be linked to taxonomic groups and bioclimatic zones.
\end{abstract}

(c) Higher Education Press 2020

\footnotetext{
* Corresponding authors

E-mail address: dehar.louis@wanadoo.fr (L. Deharveng); wudonghui@iga.ac.cn (D.Wu)
}

\section{Introduction}

Biodiversity distribution patterns are not uniform and understanding why such patterns exist is challenging ecologists and biogeographers for long (Gaston, 2000). Mountains are hotspots of research on biodiversity patterns along environ- 
mental gradients, as natural experimental fields with gradients in key abiotic factors such as temperature and moisture linked to elevation (Fischer et al., 2011). Altitudinal diversity patterns have been investigated in different areas worldwide, and in a large diversity of taxa, with a strong bias toward vertebrates and plants (Guo et al., 2013: 222 references for vertebrates and plants but only 76 for invertebrates; Wu and Lei, 2013). Changes in species diversity with altitude vary among different mountain ranges, climatic conditions, and taxonomic groups (McCain and Grytnes, 2010; Guo et al., 2013). Regarding invertebrates, most studies focused on insects with high dispersal ability, being winged (e.g., Lepidoptera, Coleoptera) or having winged reproductive stages (e.g., Formicidae) (Tykarski, 2006; Brehm et al., 2007; Choi and An, 2010; Zou et al., 2014; Ashton et al., 2016; Nowrouzi et al., 2016; Orivel et al., 2018). By contrast, soil animals typically lack wings and therefore have lower active dispersal ability, likely resulting in more clear-cut distribution patterns along altitudinal gradients (Gutierrez and Menendez, 1997). Despite their functional importance and remarkable diversity (Wardle et al., 2004; Yin et al., 2010), however, they are largely underinvestigated (Decaëns, 2010).

Changbai Mountain, the highest mountain of northeast China, offers the largest altitudinal range of well-preserved forest habitats in the region (Shen et al., 2014). It is among the most studied site worldwide for biodiversity changes with altitude in plants (Hao and Yang, 2002; Zhao et al., 2004; Cao and $\mathrm{Li}, 2008$ ) and soil microorganisms (Shen et al., 2013, 2014). Changes in the community structure of invertebrates have also been investigated. It has been shown that species richness of moths (Chen et al., 2007), groundbeetles (Zou et al., 2014), and soil mesofauna (mostly at the level of suprageneric taxa; Jiang et al., 2015) decreases with increasing altitude. This pattern is similar to that in plants (Hao and Yang, 2002), while diversity of both eukaryotic microorganisms and bacteria was correlated with $\mathrm{pH}$ rather than altitude (Shen et al., 2013, 2014). Regarding abundance, taxonomic groups of soil mesofauna in Changbai Mountain differentially respond to altitude (Jiang et al., 2015).

Collembola are the most abundant and diverse microarthropods in soil (Hopkin, 1997; Deharveng, 2004). They play important roles in soil nutrient cycling, formation of soil microstructure, improvement of soil properties, and plant litter decomposition (Rusek, 1998; Chen et al., 2007; Yang et al., 2012; Rzeszowski et al., 2017), and often respond to physical, chemical or biological changes in soil associated with altitudinal gradients (Loranger et al., 2001; Illig et al., 2010; Orivel et al., 2018). Their distribution patterns with altitude vary in the different regions investigated (Bedos, 1994; Loranger et al., 2001; Babenko, 2002; Cutz-Pool et al., 2010; Greenslade and Kitching, 2011; Maunsell et al., 2013; Sun et al., 2020). Further, different taxonomical groups of
Collembola respond differently to changing elevation (CutzPool et al., 2010; Greenslade and Kitching, 2011; Sun et al., 2020). Species of the subfamily Onychiurinae are the numerically dominant soil Collembola in Changbai Mountain (Sun and Deharveng, personal observation ${ }^{1)}$ ) and their diversity is particularly high (Sun et al., 2013a). Onychiurinae species are probably the most abundant consumers among Collembola and potentially all arthropods in the soils of Changbai Mountain, and likely regulate microbial populations and soil organic matter decomposition (Potapov and Tiunov, 2016). Furthermore, the taxonomy of the group is well known compared to other Collembola and mesofauna groups (Sun and Wu, 2011; Sun and Wu, 2012a-d; Sun et al., 2013b; Sun and $\mathrm{Li}, 2014)$. This makes them good model organisms for studying altitudinal distribution patterns.

Body size is one of the most important biological features of organisms, assumed to be linked to the environment and to have an adaptive value (Schmidt-Nielsen and Knut, 1984; Gaston et al., 2001; Woodward et al., 2005). Since Bergmann (1847) noted the positive relationship between body size and latitude among homeotherms, many studies on different animal groups have been conducted to test the validity of this "Bergmann's rule". Testing this hypothesis has been extended to non-homeotherm species on one hand, and to altitudinal patterns on the other hand. However, no clear general figure has emerged so far, and patterns in body size along altitudinal gradients remain controversial (Hawkins and DeVries, 1996; Chown and Klok, 2003; Hodkinson, 2005; Chown and Gaston, 2010). A number of hypotheses have been put forward to explain the contrasting patterns in body size relationships with temperature and latitude (Blackburn and Gaston, 1999; Stillwell, 2010; Gardner et al., 2011). However, most of them concern vertebrates (Ashton, 2002; Fu et al., 2004; Hu et al., 2011; Hsu et al., 2014; ZamoraCamacho et al., 2014); in invertebrates, changes in body size with altitude often do not follow Bergmann's rule. Rather, it has been shown to decrease with altitude in beetles and butterflies (Sømme, 1989), and a number of other studies also indicated converse-Bergmann's rule or lack of pattern (Whitman, 2008; Shelomi, 2012; Pallarés et al., 2019). The only case investigated so far among Collembola in this respect showed, conform to Bergmann's rule, that body size increases with increasing altitude in tropical montane rainforests (Sun et al., 2020).

The aim of the present study was to investigate the effects of altitude on abundance, species richness, and body size of Onychiurinae (Collembola) in temperate forests of northeast China. We hypothesized that (1) abundance and species richness of Onychiurinae in Changbai Mountain decrease with increasing altitude, following the same pattern as in other invertebrates investigated before in this area (see above), and (2) body size increases with increasing altitude in agreement

1) Among the 18 families and subfamilies of Collembola present in the Changbai dataset studied here, Onychiurinae are second to Isotomidae in species number (13 versus 23), as well as in abundance (5551 versus 7097, for a total of 19733 specimens for all Collembola). 
with Bergmann's rule, like in the tropical Collembola communities studied by Sun et al. (2020).

\section{Material and Methods}

\subsection{Study site}

Changbai Mountain is located along the border between China and North Korea, under temperate climate with a long cold winter and a short cool summer. The mean annual temperature and rainfall are $3^{\circ} \mathrm{C}$ and $700 \mathrm{~mm}$ at Erdao (591 $\mathrm{m})$, and $-7^{\circ} \mathrm{C}$ and $1400 \mathrm{~mm}$ at Tianshi (2623 $\left.\mathrm{m}\right)$, two meteorological stations of Changbai Mountain (Chen et al., 2011 ). Its highest peak at a latitude of $42^{\circ} 10^{\prime}$ is a non-active volcano reaching $2745 \mathrm{~m}$, which has generated the same homogeneous basaltic bedrock (Zhang et al., 2015), with dark brown forest soil along its forested slopes (Chen et al., 2011). The study sites were located in the Changbaishan Nature Reserve. Five distinct altitudinal vegetation types have been recognized in Changbaishan Nature Reserve (Chen et al., 2007; Bai et al., 2011; Zou et al., 2014): (1) mixed coniferous and broad-leaved forest (below $1100 \mathrm{~m}$ ), (2) mixed coniferous forest (1100 to $1500 \mathrm{~m}$ ), (3) sub-alpine mixed coniferous forest (1500 to $1800 \mathrm{~m}$ ), (4) birch forest (1800 to $2100 \mathrm{~m}$ ), and (5) tundra (above $2100 \mathrm{~m}$ ). The forests investigated span without interruption from 700 to $1800 \mathrm{~m}$, the widest altitudinal range of closed forest in Eastern China. Samples were taken in the three lower belts, which are largely mixed broadleaf and coniferous trees, and ill-delimited in the field. Only the highest sample site at $1700 \mathrm{~m}$ was almost pure coniferous forest of Abies nephrolepis Max. The vegetation zones above $1800 \mathrm{~m}$, open birch forest (up to $2100 \mathrm{~m}$ ) and alpine vegetation, were not considered as preliminary observations showed Collembola species richness and abundance to be considerably lower than that of the closed forests investigated (X. Sun, unpublished data).

\subsection{Sampling}

Seven plots were sampled every $150 \mathrm{~m}$ of elevation from 800 to $1700 \mathrm{~m}$ on a $30 \mathrm{~km}$ long transect along the western forested slopes of Changbai Mountain in September 2013 (coordinates information $-800 \mathrm{~m}: 42.07404^{\circ} \mathrm{N}, 127.52343^{\circ} \mathrm{E} ; 950 \mathrm{~m}$ : $41.86137 \mathrm{~N}^{\circ}, 127.70569^{\circ} \mathrm{E} ; 1100 \mathrm{~m}: 41.85086^{\circ} \mathrm{N}$, $127.87048^{\circ} \mathrm{E} ; 1250 \mathrm{~m}: 41.82897^{\circ} \mathrm{N}, 127.92445^{\circ} \mathrm{E} ;$ $1400 \mathrm{~m}, 41.80373^{\circ} \mathrm{N}, 127.93859^{\circ} \mathrm{E} ; 1550 \mathrm{~m}: 41.77326^{\circ} \mathrm{N}$, $\left.127.94021^{\circ} \mathrm{E} ; 1700 \mathrm{~m}: 41.75743^{\circ} \mathrm{N}, 127.94588^{\circ} \mathrm{E}\right)$. At each altitude, five samples were taken randomly. Minimum distance between the samples at each altitude was $50 \mathrm{~m}$. Samples were taken by picking up $250 \mathrm{~cm}^{3}$ of litter (thickness 2 to $5 \mathrm{~cm}$ ) using a small shovel. Soil samples were not considered in our study as the mineral soil is poorly colonized by Collembola (X. Sun, unpublished data ${ }^{1)}$ ). Litter arthropods were extracted in the laboratory using Berlese-Tullgren extractors without heating.

\subsection{Species identification}

All Onychiurinae species were sorted under the stereomicroscope, identified to species and counted. The specimens for morphological examination were cleared in lactic acid, mounted in Marc André II solution, and studied using a Nikon Eclipse 80i microscope. The identification of species was based on morphological characters according to relevant publications (Lee, 1974; Weiner, 1994; Pomorski, 2001; Pomorski and Sveenkova, 2006; Sun and Wu, 2011; Sun and Wu, 2012a-d; Sun and Zhang, 2012; Sun et al., 2013b). In the text, species richness is the number of species and abundance is the number of specimens.

\subsection{Body size}

The body shape of all Onychiurinae species of Changbai Mountain is sub-cylindrical with similar length-diameter ratio (Fig. 1), making body length a good proxy of body size. Notably, body length varies markedly among the studied Onychiurinae species, while, unlike in most Collembola (Salmon et al., 2014), other major traits are similar, i.e., they all are without furca, eyes, and pigmentation. The body length of species used for the analyses was taken from original descriptions. Species were ascribed to three length classes, i.e., large (1.46-2.30 mm), medium $(0.70-1.45 \mathrm{~mm})$ and small species $(0.45-0.69 \mathrm{~mm})$, with each comprising a similar number of species (four in the small and medium size class and five in the large size class; Table 1).

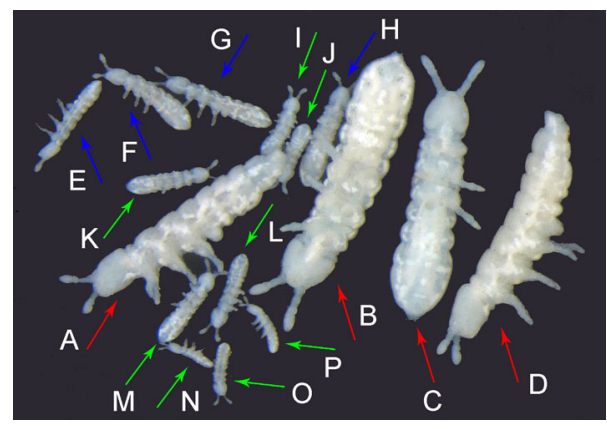

Fig. 1 Different body sizes of Onychiurinae in the study region. The color of arrows indicate the three size groups distinguished: large (red), medim (blue) and small (green). Species names: A, D: Heteraphorura seolagensis (Lee, 1974); B,C: Protaphorura changbaiensis Sun, Zhang and Wu, 2013; E-H: Allonychiurus songi Sun and Wu, 2012; I$\mathrm{P}$ : Sensillonychiurus virginis Pomorski and Sveenkova, 2006.

1) Very few individuals of Collembola have been found in soil samples. 
Table 1 Body length of the Onychiurinae species investigated in the present study.

\begin{tabular}{lll}
\hline Taxon & $\begin{array}{l}\text { Body length } \\
(\mathrm{mm})\end{array}$ & Size group \\
\hline Allonychiurus songi Sun and Wu, 2012 & $0.55-0.67$ & $\mathrm{~S}$ \\
Bionychiurus changbaiensis Sun and Wu, 2012 & $1.70-2.00$ & $\mathrm{~L}$ \\
Heteraphorura seolagensis (Lee, 1974) & 1.90 & $\mathrm{~L}$ \\
Hymenaphorura nearctica Pomorski, 2001 & $1.80-2.30$ & $\mathrm{~L}$ \\
Micraphorura sp. & 0.75 & $\mathrm{M}$ \\
Micraphorura changbaiensis Sun and Wu, 2012 & $0.70-0.82$ & $\mathrm{M}$ \\
Oligaphorura koreana (Weiner, 1994) & $1.00-1.45$ & $\mathrm{M}$ \\
Leeonychiurus gulinensis (Sun and Zhang, 2012) & $1.70-2.00$ & $\mathrm{~L}$ \\
Protaphorura changbaiensis Sun, Zhang and Wu, 2013 & $1.45-1.80$ & $\mathrm{M}$ \\
Psyllaphorura raoheensis Sun and Wu, 2013 & $0.92-1.20$ & $\mathrm{~S}$ \\
Sensillonychiurus pseudoreductus Sun and Wu, 2012 & $0.52-0.60$ & $\mathrm{~S}$ \\
Sensillonychiurus reductus Sun and Wu, 2012 & $0.50-0.60$ & $\mathrm{~S}$ \\
Sensillonychiurus virginis Pomorski and Sveenkova, 2006 & $0.45-0.50$ & \\
\hline
\end{tabular}

Body length values as in original descriptions except for Micraphorura sp. Size groups: S, small; M, medium; L, large; see text for details.

\subsection{Statistical analyses}

Sample-based accumulation curves were used to evaluate sampling exhaustivity and the predictable number of species per altitude. Prior to further statistical analyses, the number of individuals in each sample was $\log _{10}(n+1)$ transformed to improve homogeneity of variances. One-way ANOVA was performed to analyze variations with altitude in species richness, abundance, and body size. Tukey's HSD test $(\alpha<0.05)$ was used to identify significant differences between means. Linear regression analysis was carried out to inspect changes in number of species (pooled) and body size groups with altitude. The analyses were performed in R 3.4.3 using the vegan, multcomp, ggplot2 packages.

\section{Results}

\subsection{Community composition}

In total, we collected 5551 specimens of Onychiurinae comprising 13 species belonging to 10 genera (Table S1). The fauna exhibited clear relationships with that of Far-East Russia, Korea, Japan, and Western North-America. The species accumulation curve based on the pooled samples almost reached an asymptote, with only one species found in a single sample, suggesting that sampling was representative of the local Onychiurinae fauna (Fig. 2). The dominant species were Protaphorura changbaiensis at 800,950 , and $1100 \mathrm{~m}$, Sensillonychiurus virginis at 1250, 1400 and $1700 \mathrm{~m}$, and Allonychiurus songi at $1550 \mathrm{~m}$ (Fig. 1).

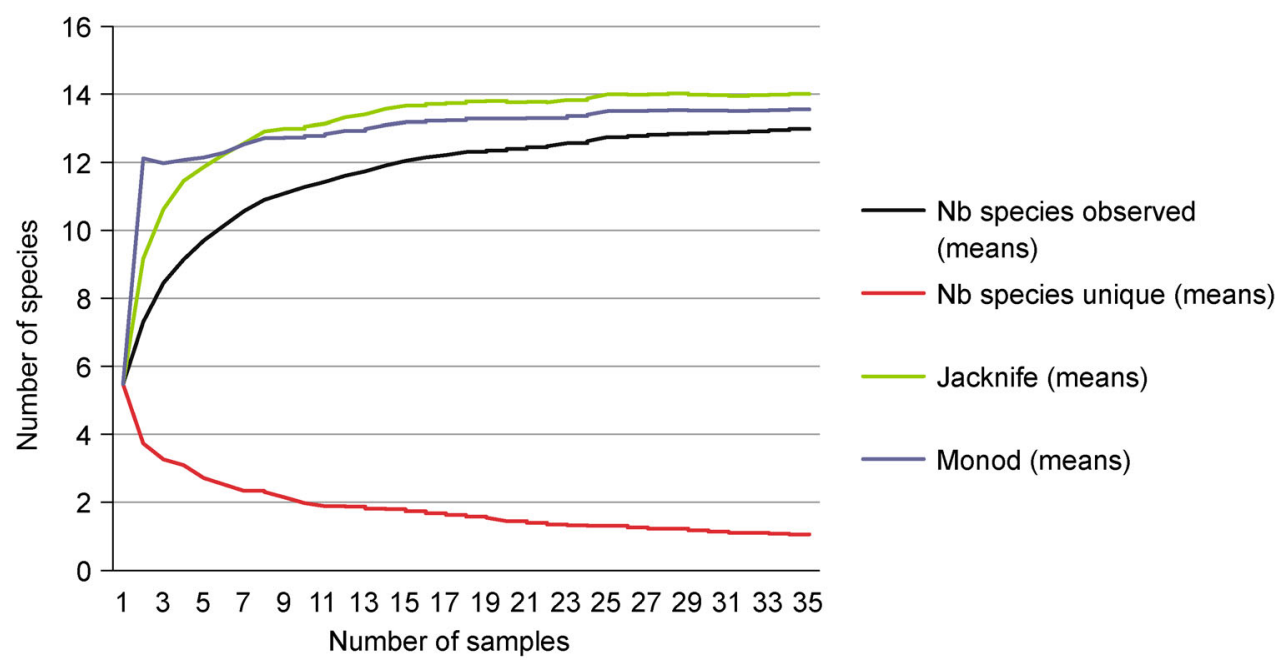

Fig. 2 Species accumulation curves of Onychiurinae of the studied altitudinal transect. Means from 50 iterations. 


\subsection{Species richness and abundance}

The pooled number of species of Onychiurinae slightly increased along the altitudinal gradient $\left(r^{2}=0.60, P=\right.$ 0.025 ) (Fig. 3A). The average number of species per sample changed significantly, but not monotonically, along the

A

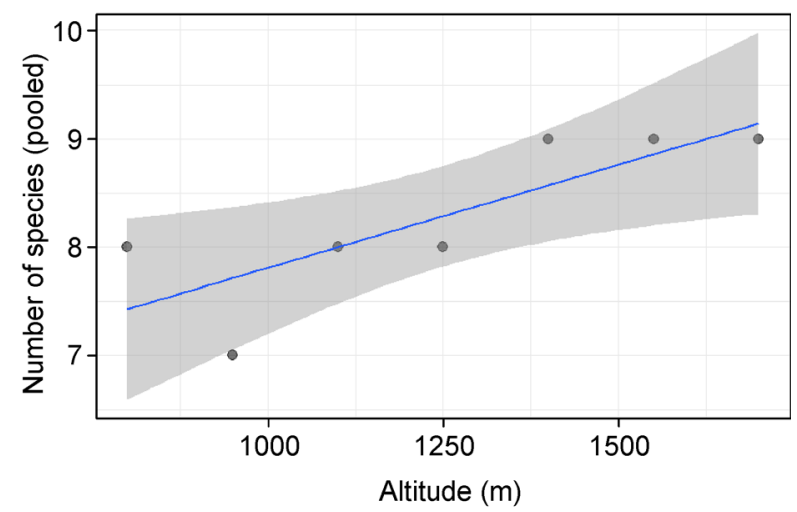

B

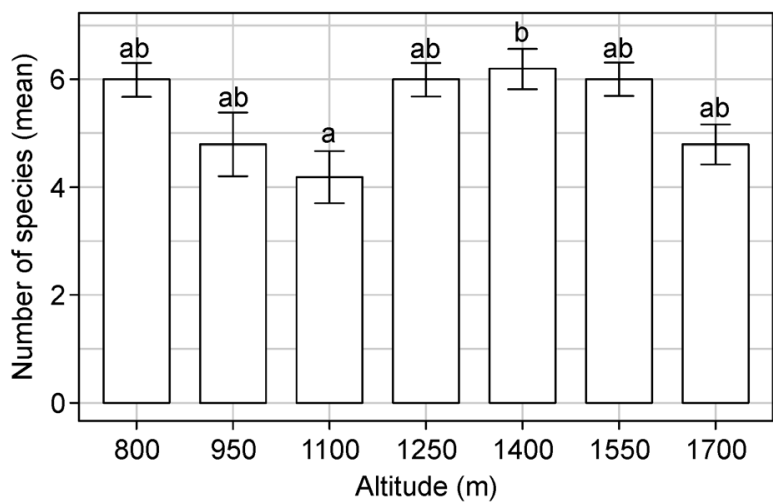

C

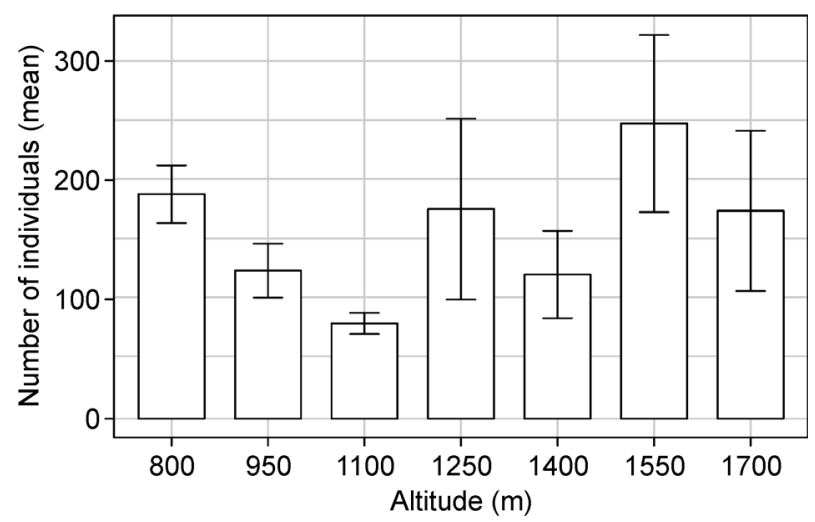

Fig. 3 Effects of the altitude on (A) the number of species pooled per altitude, (B) the mean number of species per sample, and $(C)$ the abundance of Onychiurinae along an altitudinal transect from 800 to $1700 \mathrm{~m}$ in Changbai Mountain, China; (A) blue line indicates the model prediction and gray area indicates $95 \%$ confidence interval; $(B)$ and $(C)$ means \pm SE; bars sharing the same letter do not differ significantly (Tukey's HSD test, $P<0.05)$. altitudinal gradient $(F=3.90, P=0.006)$ (Fig. 3B), being

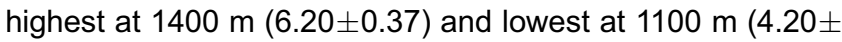
0.49 ). The abundance of Onychiurinae also followed a nonmonotonic pattern, but was not significantly correlated with altitude (Fig. 3C).

\subsection{Body size}

The mean body length of Onychiurinae species significantly varied with altitude and decreased with increasing altitude, except for the $1250 \mathrm{~m}$ site $(F=5.74, P=0.001)$ (Fig. 4). Mean body lengths were longer at lower altitudes $(1.26 \pm 0.15 \mathrm{~mm}$ at $800 \mathrm{~m}$, and $1.24 \pm 0.13 \mathrm{~mm}$ at $950 \mathrm{~m})$, and shorter at higher altitudes $(0.68 \pm 0.06 \mathrm{~mm}$ at $1250 \mathrm{~m}, 0.72 \pm 0.09 \mathrm{~mm}$ at 1550 $\mathrm{m}$, and $0.67 \pm 0.05 \mathrm{~mm}$ at $1700 \mathrm{~m}$ ) (Fig. 4). The three bodysize groups differentially responded to altitude. The abundance of the large body-size group decreased significantly from $800 \mathrm{~m}$ to $1700 \mathrm{~m}\left(r^{2}=0.57, P<0.001\right)$ (Fig. 5A); by contrast, the abundance of the small body-size group increased $\left(r^{2}=0.19, P=0.005\right)$ (Fig. 5B). The abundance of the medium-size group was not significantly correlated with altitude $\left(r^{2}=0.02, P=0.648\right)$.

\section{Discussion}

\subsection{Onychiurinae diversity across published studies}

The closest locality to Changbai Mountain where litter Collembola diversity has been studied along an altitudinal gradient is the Putorana Plateau in Siberia (Babenko, 2002). Both localities are located in the Eastern Palaearctic, their bedrock is volcanic, and their Collembola fauna is diversified from a pool of Siberian species, where Onychiurinae are dominant. They also have a similar number of Onychiurinae species along their altitudinal gradient (13 in Changbai and 12 in Putorana), in spite of very different bioclimatic conditions, with Putorana located about $20^{\circ}$ more north than Changbai

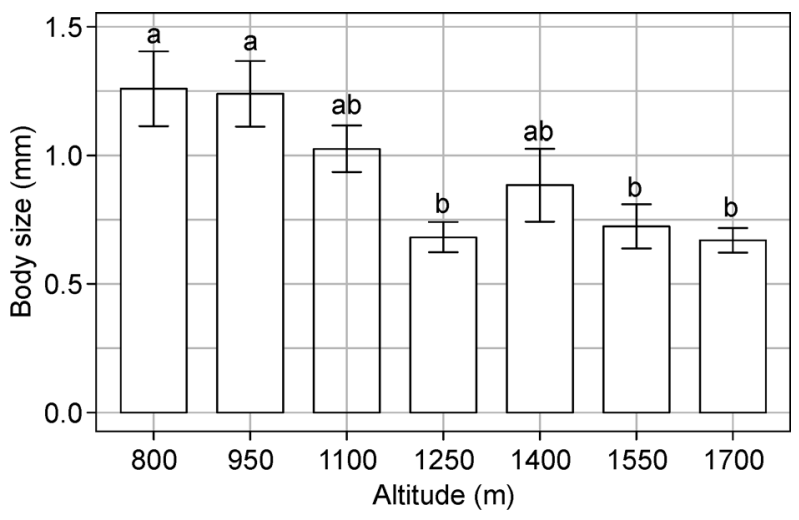

Fig. 4 Changes in body size of Onychiurinae along the studied altitudinal transect from 800 to $1700 \mathrm{~m}$ in Changbai Mountain, China; means \pm SE. Bars sharing the same letter do not differ significantly (Tukey's HSD test, $P<0.05)$. 
A

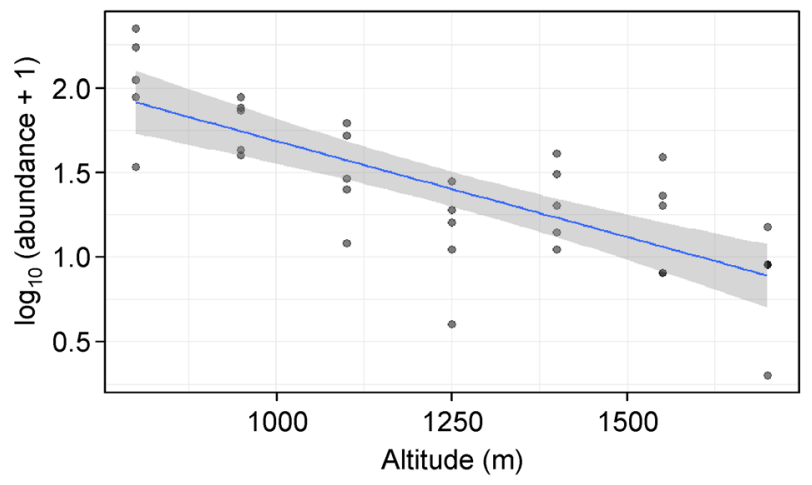

B

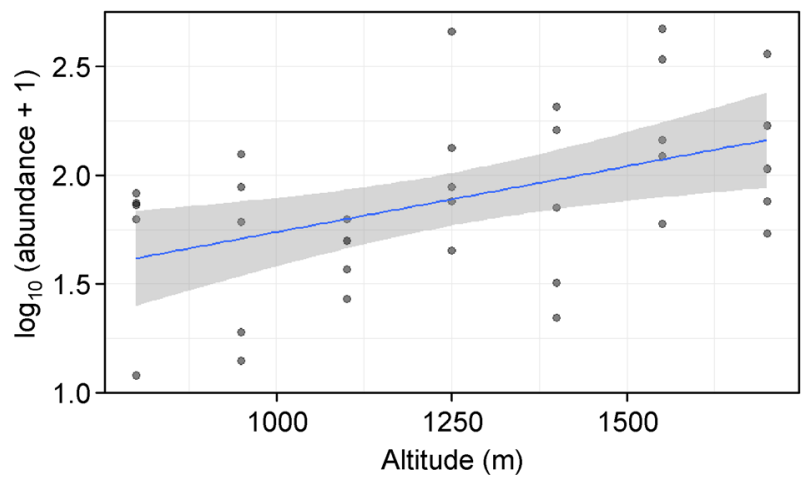

Fig. 5 Abundance $\left[\log _{10}\right.$ (abundance +1$\left.)\right]$ of $(A)$ large $(1.45-2.30 \mathrm{~mm})$ and $(B)$ small species $(0.45-0.67 \mathrm{~mm})$ of Onychiurinae along an altitudinal transect from 800 to $1700 \mathrm{~m}$ in Changbai Mountain, China; blue line indicates the model prediction and gray area indicates $95 \%$ confidence intervals.

and covered with very different vegetation. The species richness in Onychiurinae of these two localities contrasts with that reported from other altitudinal gradients documented in the literature. Eight Onychiurinae species was found by Bedos (1994) along a transect of the Doi Inthanon in tropical Thailand, but their taxonomic status remains uncertain, and most were in fact collected in soil (A. Bedos, pers.comm.). Other transects have much lower richness in litter Onychiurinae, for instance, four species in the French Alps (Loranger et al., 2001), two species in a high altitude forest in Mexico (García-Gómez et al., 2009), and a single species in the Andes of southern Ecuador (Sun et al., 2020). Greenslade and Kitching (2011) do not report any Onychiurinae in their samples collected from surface litter along temperate and tropical Australasian altitudinal transects. Overall, this is in line with the diversity pattern of the subfamily on earth, which peaks in the northern Holarctic region, with a fast decrease southwards (Sun et al., 2013a). These patterns limit straightforward comparison of factors driving the diversity of Onychiurinae in Changbai Mountain and altitudinal transects of other regions in the world.
4.2 Species diversity along the altitudinal transect

Species richness of Onychiurinae significantly varied with altitude investigated in our study, but it did not follow a monotonic nor a hump-back pattern, the dominant patterns observed previously (Guo et al., 2013). Similar to Onychiurinae in this study, species richness of the whole group of Collembola did not change in a monotonic way along an altitudinal transect in France (Loranger et al., 2001) and Tasmania (Greenslade and Kitching, 2011). Conversely, the transects analyzed by Babenko (2002) in Siberia, Cutz-Pool et al. (2010) in Mexico, and Greenslade and Kitching (2011) in Solomon islands showed a continuous decrease in the diversity of Collembola with altitude. A hump-back pattern has been reported by Loranger et al. (2001) for the French transect cited above when species numbers were pooled per altitude, and by Greenslade and Kitching (2011) for transects in Queensland and Tasmania. The study of Bedos (1994) on Collembola diversity change with altitude on the Doi Inthanon (Thailand) stands out from other studies as changes in diversity were shown to differ between soil layers, seasons, and sampling methods, with the patterns varying from humpback to a monotonic decrease with altitude. A monotonic increase in diversity with altitude has not been reported for Collembola. A pattern of increasing biodiversity could be expected among Onychiurinae in southern temperate regions of the Palaearctic where the subfamily is diversified as its species often prefer low temperatures, but this has not been observed so far. A uniform change in species richness of Collembola along altitudinal transects therefore may not exist. Rather, among other factors, patterns may be linked to biogeographic region and studied Collembola taxa. Interestingly, considering a wider taxonomic context, our results are not consistent with those observed in other invertebrates studied along altitudinal transects in Changbai Mountain, such as moths (Chen et al., 2007; Liu et al., 2007) or beetles (Zou et al., 2014), that all showed a general decrease in diversity with increasing altitude.

In addition to bioclimatic conditions, sampling design may explain in part the contrasting patterns in diversity change with altitude documented in the literature (Guo et al., 2013), as the range as well as the altitude of the studied transects for Collembola vary considerably, e.g., 60-1000 $\mathrm{m}$ for the Siberian transect (Babenko, 2002) and 2750-3440 $\mathrm{m}$ for the Mexican transect (Cutz-Pool et al., 2010). Further, the number of sampling sites investigated along altitudinal transects may also affect the patterns observed; in particular a small number of sampling sites increases the risk of missing the peak in a hump-back pattern. Our transect in Changbai Mountain ranged from 800 to $1700 \mathrm{~m}$, with seven sampled altitudes. These very important differences in sampling design might contribute to explain differences in patterns.

Beside biogeographical history, sampled habitats along altitudinal transects yield taxonomically very different collembolan communities. For instance, the transect in Mexico 
concerned moss on bark, a microhabitat particularly responsive to short-term changes in ecological conditions (Cassagnau, 1961), that is mostly populated by xero-resistant species absent in the litter. Malaise traps were used in Tasmanian sites (Greenslade and Florentine, 2013) and provided a very impoverished subset of the surface litter community sampled by pitfall traps at the same sites. At other sites, litter was sampled like in Changbai Mountain or the litter surface (Greenslade and Florentine, 2013) or litter and soil (like Loranger et al., 2001), with the collected fauna largely dominated by litter species. These Collembola communities also differed in their functional composition, e.g., the proportion of euedaphomorphic species (sensu Deharveng and Bedos, 2018), particularly Onychiurinae. A number of traits of this group are considered to be highly functional, particularly for dispersion (absence of jumping apparatus, short appendages) and sensory perception (no eyes) (Salmon et al., 2014; Pey et al., 2014). Onychiurinae are also strongly responsive to local environmental conditions such as humus form and soil chemistry, particularly acidity (Ponge, 2000; Rusek, 2007). As these conditions varied among the studied transects, the Onychiurinae data set of Changbai Mountain also cannot be compared easily to other data sets. Further studies investigating changes in functional traits along altitudinal transects and considering different taxonomic groups of Collembola are clearly needed to identify how Collembola communities adapt to changes in environmental conditions.

\subsection{Body size and altitude}

The overall morphology of Onychiurinae is rather uniform, with little variations in appendage length, pigmentation, and mouthpart structure (Pomorski, 1998; Weiner, 1996). By contrast, body size is the most obvious morphological trait that differs between many Onychiurinae species. In the present study, mean body size of Onychiurinae significantly decreased with increasing elevation, due to both the decrease in abundance of large-species and the increase in abundance of small species. These results contradict Bergmann's rule, but also results of an earlier study investigating changes in body size of Collembola in tropical montane rainforests in Ecuador, however, at these sites Onychiurinae were virtually absent (except of one species; Sun et al., 2020). Smaller body size at lower altitude in this study were hypothesized to be linked to high metabolic costs due to high temperature at low altitude which cannot be compensated for by increased feeding rate (Sun et al., 2020). A similar interpretation was given by Brehm et al. (2007) for changes in body size of Lepidoptera along a tropical altitudinal gradient in Costa Rica. These cases are in agreement, at the community level, with the temperature-size rule (Atkinson, 1994), which states that lower temperatures are associated with increasing body-size at the organism level. Increasing body size associated with increasing altitude, as predicted by Bergmann's rule, how- ever, is less common among invertebrates than the converse, and both patterns are less frequent than the no-cline pattern according to Shelomi (2012). Mousseau (1997) argued that body size often correlates with development time, resulting in a converse-Bergmann cline, i.e., decreasing body size with shorter growing season at higher altitude, and this is conform to our observations in Onychiurinae at Changbai Mountain. According to the hypothesis of Mousseau (1997), the very different patterns between the study by Sun et al. (2020) in Ecuador and the present study therefore may be related to the lack of season in the tropical forests in the Ecuador transect. Overall, considering that body size is a master trait driving fundamental characteristics of food webs, its study along altitudinal gradients under different bioclimates may allow better understanding of the factors driving elevational patterns in the community structure of Collembola and invertebrates in general.

\section{Conclusion}

In summary, richness, abundance, and body size of Onychiurinae in the Changbai Mountain range of northeast China respond differently to altitude. The pooled number of species slightly increased, while the average number of species per sample changed significantly, but not monotonically, along the altitudinal gradient. By contrast, the abundance of Onychiurinae was not significantly correlated with altitude. The mean body length of Onychiurinae decreased significantly with increasing altitude contradicting Bergmann's rule. Further, Onychiurinae of different body-size did not respond in the same way to altitude, e.g., the abundance of Onychiurinae of large body-size decreased significantly with increasing altitude, whereas the abundance of Onychiurinae of small body-size increased. Our results are not consistent with those observed in other invertebrates studied along altitude in this region, nor with patterns observed in different groups of Collembola from other biogeographic regions. The proposition that Collembola generally follow Bergmann's rule or any common pattern is clearly challenged by available studies. The results suggest that to improve understanding of the drivers of the observed patterns further investigations on changes in Collembola communities along altitudinal gradients should consider different taxonomic groups and bioclimatic contexts and use similar sampling designs.

\section{Acknowledgments}

This work was supported by the National Natural Science Foundation of China (grant numbers 41571052, 41811530086, 41811530279, 31861133006), the 2013-2015 CoopIntEer CNRSNSFC projects between China and France, the German Research Foundation (DFG; SCHE 376-42/1), and the funding provided by Alexander von Humboldt Foundation (Germany). 


\section{Confict of interest}

The authors declare that they have no conflict of interest.

\section{Author contributions}

Xin Sun, Louis Deharveng, and Donghui Wu conceived the experiments; Xin Sun, Louis Deharveng, Anne Bedos, and Liang Chang contributed to the interpretation of the results; Xin Sun and Louis Deharveng and took the lead in writing the manuscript; Stefan Scheu provided valuale advices and linguistic revision during the preparation of the manuscript. All authors discussed the results and contributed to the final manuscript.

\section{Electronic supplementary material}

Supplementary material is available in the online version of this article at https://doi.org/10.1007/s42832-020-0040-8 and is accessible for authorized users.

\section{References}

Ashton, K.G., 2002. Do amphibians follow Bergmann's rule? Canadian Journal of Zoology 80, 708-716.

Ashton, L.A., Odell, E.H., Burwell, C.J., Maunsell, S.C., Nakamura, A., Mcdonald, W.J.F., Kitching, R.L., 2016. Altitudinal patterns of moth diversity in tropical and subtropical Australian rainforests. Austral Ecology 41, 197-208.

Atkinson, D., 1994. Temperature and organism size - A biological law for ectotherms. Advances in Ecological Research 25, 1-58.

Babenko, A.B., 2002. Springtails of Western Putorana Plateau (Middle Siberia): fauna and altitude differentiation of assemblages. Entomological Review 82, 901-919.

Bai, F., Sang, W.G., Axmacher, J.C., 2011. Forest vegetation responses to climate and environmental change: A case study from Changbai Mountain, NE China. Forest Ecology and Management 262, 2052-2060.

Bedos, A., 1994. Edaphic Collembola of Doi Inthanon, Thailand: biodiversity and ecology in tropical forest. Unpubl. Doctoral Thesis, Université Paul Sabatier, Toulouse, France. (in French)

Bergmann, C., 1847. About the relationships between body-heatregulation of animals and their body-size. Gottinger Studies 3, 595-708. (in German)

Blackburn, T.M., Gaston, K.J., 1999. The relationship between animal abundance and body size: a review of the mechanisms. Advances in Ecological Research 28, 181-210.

Brehm, G., Colwell, R.K., Kluge, J., 2007. The role of environment and mid-domain effect on moth species richness along a tropical elevational gradient. Global Ecology and Biogeography 16, 205 219.

Cao, W., Li, Y.Y., 2008. Vertical pattern of flora from Changbai Mountain, China. Journal of Beijing Forestry University 5, 53-58. (in Chinese)

Cassagnau, P., 1961. Ecology of soil in central Pyrenees. Biocenoses of Collembola. Paris: Herman. (in French)
Chen, L., Wu, S., Pan, T., 2011. Variability of climate-growth relationships along an elevation gradient in the Changbai Mountain, northeastern China. Trees (Berlin) 25, 1133-1139.

Chen, Y., Hou, G., Meng, Q., Ai, G., Meng, Q., Gao, W., 2007. On vertical distribution and fauna of the geometrid moth in Changbai Mountain. Journal of Beihua University 8, 73-79 (Natural Science).

Choi, S.W., An, J.S., 2010. Altitudinal distribution of moths (Lepidoptera) in Mt. Jirisan National Park, South Korea. European Journal of Entomology 107, 229-245.

Chown, S.L., Gaston, K.J., 2010. Body size variation in insects: a macroecological perspective. Biological Reviews of the Cambridge Philosophical Society 85, 139-169.

Chown, S.L., Klok, C.J., 2003. Altitudinal body size clines: latitudinal effects associated with changing seasonality. Ecography 26, 445455.

Cutz-Pool, L.Q., Palacios-Vargas, J.G., Cano-Santana, Z., CastañoMeneses, G., 2010. Diversity patterns of Collembola in an elevational gradient in the NW slope of Iztaccíhuatl volcano, state of Mexico, Mexico. Entomological News 121, 249-261.

Decaëns, T., 2010. Macroecological patterns in soil communities. Global Ecology and Biogeography 19, 287-302.

Deharveng, L., 2004. Recent advances in Collembola systematics. Pedobiologia 48, 415-433.

Deharveng, L., Bedos, A., 2018. Diversity of Terrestrial Invertebrates in Subterranean Habitats. In: Moldovan, O., Kovac, L., Halse, S., eds. Cave Ecology, Ecological Studies 235. Springer Nature Switzerland AG, 107-172.

Fischer, A., Blaschke, M., Bassler, C., 2011. Altitudinal gradients in biodiversity research: the state of the art and future perspectives under climate change aspects. Forest Ecology, Landscape Research and Conservation 11, 5-17.

Fu, C.Z., Wu, J.H., Wang, X.Y., Lei, G.C., Chen, J.K., 2004. Patterns of diversity, altitudinal range and body size among freshwater fishes in the Yangtze River basin, China. Global Ecology and Biogeography 13, 543-552.

García-Gómez, A., Castaño-Meneses, G., Palacios-Vargas, J.G., 2009. Diversity of springtails (Hexapoda) according to a altitudinal gradient. Pesquisa Agropecuária Brasileira 44, 911-916.

Gardner, J.L., Peters, A., Kearney, M.R., Joseph, L., Heinsohn, R., 2011. Declining body size: a third universal response to warming? Trends in Ecology \& Evolution 26, 285-291.

Gaston, K.J., 2000. Global patterns in biodiversity. Nature 405, 220 227.

Gaston, K.J., Chown, S.L., Mercer, R.D., 2001. The animal speciesbody size distribution of Marion Island. Proceedings of the National Academy of Sciences of the United States of America 98, 1449314496.

Greenslade, P., Florentine, S., 2013. Collembola (springtails). In: Driessen, M., Mallick, S., eds. The Distributions of Invertebrate Species Along the Warra-Mount Weld Altitudinal Transect in 20012002 and Identification of Taxa Restricted by Altitude. Nature Conservation Report 13/4, Department of Primary Industries, Parks, Water and Environment, Hobart (Australia), 24-38.

Greenslade, P., Kitching, R.L., 2011. Potential effects of climatic warming on the distribution of Collembola along an altitudinal transect in Lamington National Park, Queensland, Australia. 
Memoirs of the Queensland Museum. Nature 55, 333-347.

Guo, Q., Kelt, D.A., Sun, Z., Liu, H., Hu, L., Ren, H., Wen, J., 2013. Global variation in elevational diversity patterns. Scientific Reports 3, 3007.

Gutierrez, D., Menendez, R., 1997. Patterns in the distribution, abundance and body size of carabid beetles (Coleoptera: Caraboidea) in relation to dispersal ability. Journal of Biogeography 24, 903-914.

Hao, Z.Q., Yang, X.M., 2002. Alpha diversity of communities and their variety along altitude gradient on northern slope of Changbai Mountain. Ying Yong Sheng Tai Xue Bao 13, 786-789.

Hawkins, B.A., DeVries, P., 1996. Altitudinal gradients in the body sizes of Costa Rican Butterflies. Acta Ecologica 17, 185-194.

Hodkinson, I.D., 2005. Terrestrial insects along elevation gradients: species and community responses to altitude. Biological Reviews of the Cambridge Philosophical Society 80, 489-513.

Hopkin, S.P., 1997. Biology of the springtails: (Insecta: Collembola). New York: Oxford University Press.

Hsu, F.H., Hsieh, Y.S., Wu, S.H., Kam, Y.C., 2014. Altitudinal variation in body size and age structure of the Sauter's frog Rana sauteri in Taiwan. Zoological Studies 53, 62.

Hu, J.H., Xie, F., Li, C., Jiang, J.P., 2011. Elevational patterns of species richness, range and body size for spiny frogs. PLoS One 6, e19817.

Illig, J., Norton, R.A., Scheu, S., Maraun, M., 2010. Density and community structure of soil- and bark-dwelling microarthropods along an altitudinal gradient in a tropical montane rainforest. Experimental \& Applied Acarology 52, 49-62.

Jiang, Y.F., Yin, X.Q., Wang, F.B., 2015. Composition and spatial distribution of soil mesofauna along an elevation gradient on the north slope of the Changbai Mountains, China. Pedosphere 25, 811-824.

Lee, B.H., 1974. Study of the Korean fauna of Collembolan Insects III. Description of eight new species of Neanuridae and Onychiuridae. Bulletin du Muséum National d'Histoire Naturelle, Paris, 3 Série 220, 573-598. (in French)

Liu, S.D., Meng, Q.F., Gao, W.T., 2007. Moth diversity in the northern slope of Changbai Mountain Nature Reserve. Dongbei Linye Daxue Xuebao 35, 51-53. (in Chinese)

Loranger, G., Bandyopadhyaya, I., Razaka, B., Ponge, J.F., 2001. Does soil acidity explain altitudinal sequences in collembolan communities? Soil Biology \& Biochemistry 33, 381-393.

Maunsell, S.C., Kitching, R.L., Greenslade, P., Nakamura, A., Burwell, C.J., 2013. Springtail (Collembola) assemblages along an elevational gradient in Australian subtropical rainforest. Australian Journal of Entomology 52, 114-124.

McCain, C.M., Grytnes, J.A., 2010. Elevational gradients in species richness. In: Encyclopedia of Life Sciences (ELS). Chichester: John Wiley \& Sons, Ltd.

Mousseau, T.A., 1997. Ectotherms follow the converse to Bergmann's rule. Evolution; International Journal of Organic Evolution 51, 630 632.

Nowrouzi, S., Andersen, A.N., Macfadyen, S., Staunton, K.M., VanDerWal, J., Robson, S.K., 2016. Ant diversity and distribution along elevation gradients in the Australian wet tropics: the importance of seasonal moisture stability. PLoS One 11, e0153420.

Orivel, J., Klimes, P., Novotny, V., Leponce, M., 2018. Resource use and food preferences in understory ant communities along a complete elevational gradient in Papua New Guinea. Biotropica $50,641-648$.

Pallarés, S., Lai, M., Abellán, P., Ribera, I., Sánchez-Fernández, D., 2019. An interspecific test of Bergmann's rule reveals inconsistent body size patterns across several lineages of water beetles (Coleoptera: Dytiscidae). Ecological Entomology 44, 249-254

Pey, B., Nahmani, J., Auclerc, A., Capowiez, Y., Cluzeau, D., Cortet, J., Decaëns, T., Deharveng, L., Dubs, F., Joimel, S., Briard, C., Grumiaux, F., Laporte, M.A., Pasquet, A., Pelosi, C., Pernin, C., Ponge, J.F., Salmon, S., Santorufo, L., Hedde, M., 2014. Current use of and future needs for soil invertebrate functional traits in community ecology. Basic and Applied Ecology 15, 194-206.

Pomorski, R.J., 1998. Onychiurinae of Poland (Collembola: Onychiuridae). Wrocklaw: Polish Taxonomical Society.

Pomorski, R.J., 2001. Review of the genus Hymenaphorura Bagnall, 1948 with description of eleven new species from North America and Siberia (Collembola: Onychiuridae). Insect Systematics \& Evolution 32, 439-474.

Pomorski, R.J., Sveenkova, Y.B., 2006. New genus with three new species of Thalassaphorurini (Collembola: Onychiuridae) from Russian Far East. Insect Systematics \& Evolution 37, 191-196.

Ponge, J.F., 2000. Vertical distribution of Collembola (Hexapoda) and their food resources in 20 organic horizons of beech forests. Biology and Fertility of Soils 32, 508-522.

Potapov, A.A., Tiunov, A.V., 2016. Stable isotope composition of mycophagous collembolans versus mycotrophic plants: do soil invertebrates feed on mycorrhizal fungi? Soil Biology \& Biochemistry $93,115-118$.

Rusek, J., 1998. Biodiversity of Collembola and their functional role in the ecosystem. Biodiversity and Conservation 7, 1207-1219.

Rusek, J., 2007. A new classification of Collembola and Protura life forms. In: Tajovský, K., Schlaghamerský, J., Pižl, V., eds. Contributions to Soil Zoology in Central Europe II. Biological Centre AS CR- Institute of Soil Biology: České Budějovice, 109115.

Rzeszowski, K., Zadrożny, P., Nicia, P., 2017. The effect of soil nutrient gradients on Collembola communities inhabiting typical urban green spaces. Pedobiologia 64, 15-24.

Salmon, S., Ponge, J.F., Gachet, S., Deharveng, L., Lefebvre, N., Delabrosse, F., 2014. Linking species, traits and habitat characteristics of Collembola at European scale. Soil Biology \& Biochemistry 75, 73-85.

Schmidt-Nielsen, K., Knut, S.N., 1984. Scaling: why is animal size so important? New York: Cambridge University Press.

Shelomi, M., 2012. Where are we now? Bergmann's rule sensu lato in insects. American Naturalist 180, 511-519.

Shen, C.C., Liang, W.J., Shi, Y., Lin, X.G., Zhang, H.Y., Wu, X., Xie, G., Chain, P., Grogan, P., Chu, H.Y., 2014. Contrasting elevational diversity patterns between eukaryotic soil microbes and plants. Ecology 95, 3190-3202.

Shen, C.C., Xiong, J.B., Zhang, H.Y., Feng, Y.Z., Lin, X.G., Li, X.Y., Liang, W.J., Chu, H.Y., 2013. Soil pH drives the spatial distribution of bacterial communities along elevation on Changbai Mountain. 
Soil Biology \& Biochemistry 57, 204-211.

Sømme, L., 1989. Adaptations of terrestrial arthropods to the alpine environment. Biological Reviews of the Cambridge Philosophical Society $64,367-407$.

Stillwell, R.C., 2010. Are latitudinal clines in body size adaptive? Oikos 119, 1387-1390.

Sun, X., Deharveng, L., Bedos, A., Wu, D.H., Chen, J.X., 2013a. Onychiuridae of China: species versus generic diversity along a latitudinal gradient. Soil Organisms 85, 51-59.

Sun, X., Li, Y., 2014. New Chinese record of the genus Spinonychiurus (Collembola, Onychiuridae), with the description of a new species. ZooKeys 439, 19-26.

Sun, X., Marian, F., Bluhm, C., Maraun, M., Scheu, S., 2020. Response of Collembola to the addition of nutrients along an altitudinal gradient of tropical montane rainforests. Applied Soil Ecology 147, 103382.

Sun, X., Wu, D.H., 2011. Two new species of the tribe Hymenaphorurini Pomorski, 1996 (Collembola: Onychiuridae) from Northeast China. Entomological News 122, 441-450.

Sun, X., Wu, D.H., 2012a. A new species and a new record species in the tribe Thalassaphorurini Pomorski, 1998 (Collembola: Onychiuridae) from northeast China. Entomotaxonomia 34, 495502.

Sun, X., Wu, D.H., 2012b. Two new species of the genus Sensillonychiurus Pomorski et Sveenkova, 2006 (Collembola: Onychiuridae) from Changbai Mountains, China. Annales Zoologici (Warszawa) 62, 563-570.

Sun, X., Wu, D.H., 2012c. Review of Chinese Oligaphorurini (Collembola, Onychiuridae) with descriptions of two new Palaearctic species. ZooKeys 192, 15-26.

Sun, X., Wu, D.H., 2012d. The genus Bionychiurus Pomorski, 1996 (Collembola: Onychiuridae) in China. Annales Zoologici (Warszawa) 62, 357-362.

Sun, X., Zhang, B., Wu, D.H., 2013b. Two new species and one new country record of Protaphorura Absolon, 1901(Collembola: Onychiuridae) from northeast China. Zootaxa 3693, 207-220.

Sun, X., Zhang, F., 2012. Two new species of Onychiurus (Collembola: Onychiuridae) from Eastern China, Journal of Natural History 46, 31-32, 1895-1904.

Tykarski, P., 2006. Beetles associated with scolytids (Coleoptera, Scolytidae) and the elevational gradient: Diversity and dynamics of the community in the Tatra National Park, Poland. Forest Ecology and Management 225, 146-159.

Wardle, D.A., Bardgett, R.D., Klironomos, J.N., 2004. Ecological linkages between aboveground and belowground biota. Science 304, 1629-1633.

Weiner, M.W., 1994. Onychiurinae Bagnall of North Korea: species with small postantennal organs (Collembola, Onychiuridae). Bulletin de la Société Entomologique de France 99, 31-40.

Weiner, W.M., 1996. Generic revision of Onychiurinae (Collembola: Onychiuridae) with a cladistic analysis. Annals of the Entomological Society of France, New Series 32, 163-200.

Whitman, D.W., 2008. The significance of body size in the Orthoptera: a review. Journal of Orthoptera Research 17, 117-134.

Woodward, G., Ebenman, B., Emmerson, M., Montoya, J.M., Olesen, J.M., Valido, A., Warren, P.H., 2005. Body size in ecological networks. Trends in Ecology \& Evolution 20, 402-409.

Wu, Y.J., Lei, F.M., 2013. Species richness patterns and mechanisms along the elevational gradients. Chinese Journal of Zoology 48 , 797-807 (in Chinese).

Yang, X., Yang, Z., Warren, M.W., Chen, J., 2012. Mechanical fragmentation enhances the contribution of Collembola to leaf litter decomposition. European Journal of Soil Biology 53, 23-31.

Yin, X.Q., Song, B., Dong, W.H., Xin, W.D., Wang, Y., 2010. A Review on the eco-geography of soil fauna in China. Acta Geographica Sinica 65, 91-102.

Zamora-Camacho, F.J., Reguera, S., Moreno-Rueda, G., 2014. Bergmann's Rule rules body size in an ectotherm: heat conservation in a lizard along a 2200-metre elevational gradient. Journal of Evolutionary Biology 27, 2820-2828.

Zhang, M., Guo, Z., Cheng, Z., Zhang, L., Liu, J., 2015. Late Cenozoic intraplate volcanism in Changbai volcanic field, on the border of China and North Korea: insights into deep subduction of the Pacific slab and intraplate volcanism. Journal of the Geological Society 172, 648-663.

Zhao, S.Q., Fang, J.Y., Zong, Z.J., Zhu, B., Shen, H.H., 2004. Composition, structure and species diversity of plant communities along an altitudinal gradient on the northern slope of Mt. Changbai, Northeast China. Shengwu Duoyangxing 12, 164-173 (in Chinese).

Zou, Y., Sang, W.G., Zhou, H.C., Huang, L.Y., Axmacher, J.C., 2014. Altitudinal diversity patterns of ground beetles (Coleoptera: Carabidae) in the forests of Changbai Mountain, Northeast China. Insect Conservation and Diversity 7, 161-171. 